URL: http://dergipark.ulakbim.gov.tr/ijhbs/index

Volume: 2, Issue: 1, Year: 2016

DOI: http://dx.doi.org/10.19148/ijhbs.02348

\title{
An Integrated Approach of Erikson's Psychosocial Theory and Adlerian Counseling
}

\author{
Bekir Çelik \\ Çanakkale Onsekiz Mart University, Turkey \\ celik@comu.edu.tr \\ Enes Ergün \\ Çanakkale Onsekiz Mart University, Turkey \\ enes.ergun@comu.edu.tr
}

\begin{abstract}
This study aims to integrate Erikson's psychosocial theory and Adler's individual psychology. Adler and Erikson have complimentary descriptions of personality and they both view mankind as a social being in nature, having a desire to belong and motivated for significance in their social environment in order to handle with inferiority. The integration also suggests that four main areas should be taken in consideration during the counseling process: work, friendship, sexual love, and optimism. This integration concerned with relatively normal individuals who function properly in most situations but are troubled by one or two specific concerns and the focus is on the reality and the present. Resolving unconscious conflicts from the client's past life is not the goal of this orientation, but helping client with today's situation. Ideological identity is another important aspect of this integration which includes domains of occupation, religion, politics, and philosophical lifestyle.
\end{abstract}

Keywords: Adler, Erikson, multicultural counseling, ego psychology

\section{Introduction}

In the last decades an effort among researchers to integrate different theoretical models has emerged. Thrived on the fertile grounds of multicultural approach, these efforts have been trying to build bridges among different theoretical frameworks. With this main goal in mind, the purpose of the present article is to highlight the integration of Adlerian theory and Erikson's psychosocial theory.

Adler's individual theory and Erikson's ego psychology were assumed to be the best theories to work with, since they both highlighted the importance of the social experiences for humans' lives. Both theorists somehow influenced from Freudian perspective of development but Erikson elaborated the stages and embrace the whole life with his psychosocial theory. Adler stayed away from stages but emphasized continuously operating set of dynamics such as compensating for inferiority feelings. Erikson's psychosocial theory and his thoughts about the ego development share similar perspective with Adler's theory. While Erikson's theory gives the theoretical background of this integration, Adler's theory mainly supports with its practical applications.

Theories of Adler and Erikson have complimentary descriptions of personality and they both view mankind as a social being in nature, with a desire to belong and strive for significance in their 
social environment which inspired us to integrate these theories. Ego psychology emphasizes that humans are not victims of their past experiences, but they have an innate potential to understand and adapt their environment. According to Erikson, children are not merely passive beings who are molded by their parents, they are active explorers who seek to control the environment around them and adapt different conditions. In a similar way, Adler saw humans as both creators and creation of their own style of lives which is the expression of their selected goals (Corey, 2013). According to Erikson, humans must first understand the realities of the social world in order to adapt effectively and show a normal pattern of personal growth, because of this belief, Erikson has been labelled as an ego psychologist (Shaffer, 1985). Erikson and Adler, together explain and guide the use of the counseling and psychotherapeutic relationship to foster client's positive development within their social context.

In this article, the basic concepts of Erikson's psycho-social model and Adlerian theory are summarized by focusing on the related aspects of each theory, which in turn will contribute to the integration of these theories.

\section{Basic Concepts}

Adler and Erikson have the same theoretical origin and they consistently expanded psychoanalytic theory in a parallel direction to each other. Both theorists consider the social as well as the creative self or ego processes as being not less important than biological-self. Adler even described later personality development in childhood as evolution of "style of life" and Erikson designated same later development as the evolution of "ego identity" (Massey, 1986). The environment that children live in was one of the important aspects of their theories. In his studies, Adler focused on children with regard to their guardians while Erikson gave importance to child development in terms of interpersonal and cultural influences.

Another similarity is that both theorists underlined the importance of personal growth rather than defense of the self in "the healthy personality". According to Adler, individuals create their own goals for living and act as if their goals are the final purpose of their life, and both emphasized the dynamic, organizing processes of personality rather than isolatable structures or symptoms (Sharf, 2000; Prochaska \& Norcross, 1999). Besides, de Man and Efraim (1988) outlined that personality theorists (e.g., Adler, Erikson, Maslow) had emphasized the importance of the ability of social cooperation. Being a responsible and participating member of the society is often seen as a sign of maturity; as a result, both Adler and Erikson focused specifically on "growth psychology", which makes Adler and Erikson assumed to be the members of the "third force" in psychology.

Many researchers accepted that most of the theorists had mediocre roles in integrating the theories of Freud and Adler. Erikson, as well, can be included in this category that his theory considered oral, anal, phallic, and genital issues as the constitutional foundations for ego development. However, he emphasized social variables (peer, group, family, etc.) as essential to ego development in the way of revealing of Adler's concerns (Schultz \& Liptak, 1998).

Freud emphasized that human behavior basically stemmed from conflicts between the id and the superego; conversely, Erikson believed that human beings are rational creatures and their thoughts, feelings, and actions are largely controlled by the ego. Moreover, according to Erikson, ego is more than a mediator between the id and the superego (Tenentes, 1991). Adler regarded the ego or self as it is "creator". For Erikson, the ego creates a unified and unique identity, a process that echoes Adler's focus on the creation of a unique and unified style of life. Similar with Adler's "style of life", Erikson's developing "ego identity" incorporates structural influences, perceptions of the world and self, interpersonal orientations, and patterns of problem solving (Sharf, 2000). 
Specifically, it can be claimed that Erikson and Adler complement each other's theories regarding human development, social interest, temporal emphasis, relations in a group, gender influences on personality, and the role of values in human existence.

\section{Theory of Personality}

Both Adler and Erikson stress the development of self-identity within a social context that provides an orientation toward or against constructive communal living. Adler expanded on how every person experiences inferiority feelings and endeavors to turn a negative situation to a positive one. The neurotic attempts compensate inferiority feelings both by acting superior and by employing safeguarding strategies to camouflage a faltering self-esteem. The person, both builds a solid sense of self-esteem by excelling at life's tasks and by expressing social interest toward others (Watts, 1996).

Erikson's focus on identity as "a psycho-social process which presumes some essential features in the individual as well as his society" moves beyond the psychoanalytic approach to character as a biologically determined "closed inner system" (Weiland, 1993).

Erikson has accented the theme of socio-cultural influences in human development. Lee (2002) stressed that mutual regulation among pre-schoolers, the cooperation necessary for productivity, constructing mutually satisfying relationships during youth, the love of young adults, and the caring expressed by adults all embody what Adler termed "social interest". The processes of fidelity, intimacy, generativity, and wisdom cannot proceed without social interest. Adler first elaborated on the social aspects of personality and Erikson has incorporated this emphasis into his conceptualization of the development of ego identity.

\section{Psychopathology: Inferiority and Self-Esteem}

Adler focuses on inferiority and he saw those inferiority feelings as normal feelings of all people, beside Adler's psychotherapy states that pathological personalities are those who have become discouraged from being able to attain superiority in a socially constructive style. Pathological personalities tend to emerge from family atmosphere of competition and distrust, neglect, domination, abuse or pampering all of which discourage social interest. Thus, Adlerian theory tries to point out main characteristics of a healthy or neurotic style of life to challenge normal feeling of inferiority. This is parallel to Erikson's point of view that an ego identity can evolve toward either a positive or negative resolution in each stage of psycho-social development and in each stage individuals handle with specific crisis. (Sharf, 2000; Prochaska \& Norcross, 1999).

Failure to advance and consolidate ego identity at any age leaves a maladjustment that may be experienced as an inferiority feeling and/or give rise to an impairment that others may perceive as handicapped social relations and self-enhancement. Each stage that Erikson describes present a crisis around which some failure of fulfillment leaves vulnerabilities which Adler discussed as experiences of inferiorities that may prompt compensatory strivings for superiority or coalesce into an inferiority or superiority complex. Furthermore, Erikson explicitly recognizes the roles of inferiority feelings in his fourth stage as "industry vs. inferiority". Failure to develop a sense of industry leads to a sense of inadequacy and inferiority. A sense of inferiority can lead to symptoms such as depression, anxiety or avoidance of achievement (Weiland 1993; Thomas, 2011).

Erikson notes that the school-age child who becomes alienated from learning tasks may experience "a sense of inferiority" because of wanting "mommy more than knowledge", preferring "to be the baby at home rather than the big child at school," and still comparing himself with his father, thus arousing a "sense of guilt as well as a sense of inferiority" (Weiland, 1993; Thomas, 2011). While Erikson's ideas retain a reliance on Freudian oedipal explanations, they also acknowledge the school-age as more than a "latency". The school-age child feels either 
"industrious" (high in self-esteem) by knowing, by making, and by doing well, or "inferior" (low in self-esteem) by failing to accomplish valued tasks and goals (Lee, 2002).

\section{Therapeutic Content}

The aim of the therapy is to help individuals change self-defeating behaviors, solve problems more efficiently and increase in client's social interest and the quality of their life. Therapists can look for specific maladaptive behaviors to help their clients to understand them, and also they can use their expertise in order to not only help clients understand how certain behaviors has been maladaptive, but also learn new patterns of behavior to adapt social life. The ego functions cope with the environment through the use of reasoning and conscious thought. Ego analysts have a greater tendency to view the functions of the ego in a more positive manner. Psycho-social stages can be matched with a related ego strength such as hope from trust, will from autonomy, purpose from initiative, competence from industry, fidelity from identity, love from intimacy, care from generativity, and wisdom from integrity (Corey, 2013; Sharf, 2000; Prochaska \& Norcross, 1999). This is similar with the Adlerian therapeutic process which is being fully aware of the overall pattern of their lifestyles and goals. Another similarity between the theories is establishing a consolidate ego identity in ego psychology and creative-self in Adlerian psychology; so growth and development occur intrapsychically and interpersonally in persons' interactions with the environment. This process is called "social interest" in Adlerian therapy and is the main goal of this integrative counseling.

Counseling strives to improve a person's capacity in different four tasks:

Work: Adler proposed as the main avenues to gaining self-esteem take on a developmental dimension when viewed from Erikson's life-cycle perspective. Erikson's psycho-social theory mentions the "work" in different forms at various stages. The fourth stage of the theory centers on being productive in one's culture. Children in this stage gain a sense of industriousness by becoming a competent member in the society. Children also become industrious by exercising the abilities considered necessary in the systematic "instruction in production" (e.g., schooling) that each culture offers its younger members. A child, alienated from the technology which is necessary to survive and form the self"s capacity for competence, experiences "inferiority" and impoverished self-esteem (Thomas, 2011). Adolescents consolidate an ego identity in Erikson's fifth stage and they depend partly on choosing a personally meaningful and economically practical orientation to work.

Friendship: According to Adler, people were born with the capacity and need to be connected with each other and develop close relationship with others. Intimate partners both express social interest toward each other and rely on other to exercise social interest. During the adulthood, remaining generativity is aided by vitalizing friendships and parenting which are enriched by social network support (Lee, 2002).

Sexual Love: Erikson refers to the discovery of anatomical differences but highlights other developments, such as the initial understanding of female and male roles. During this stage he also notes the increase in the powers of self-guidance that become embodied in a conscience (Thomas, 2011).

Optimism: Erikson's notion of progressive development throughout psychosocial stages is parallel to Adler's optimism in regard to the possibility of change. If the present brings increased generative influences (more abundant social interest) from caring adults or loving peers, then earlier inferiorities can be reduced, within reasonable limits, as the ego identity (the self) grows into a fuller measure of self-esteem (Tenentes, 1991). Five questions of the ego-oriented assessment are important guide to the practitioners during the assessment of ego strength (Goldstein, 1995): 
1. To what extent is the client's problem a function of stresses imposed by his current life roles or developmental tasks?

2. To what extent is the client's problem a function of situational stress or of a traumatic event?

3. To what extent is the client's problem a function of impairments in his ego capacities or of developmental difficulties or dynamics?

4. To what extent is the client's problem a function of the lack of environmental resources or supports or of a lack of fit between his inner capacities and his external circumstances? 5. What inner capacities and environmental resources does the client have that can be mobilized to improve his functioning?

Assessing the ego strength with this guide can help practitioners to determine the direction of the intervention. As Markstorm \& Hunter (1999) and Bjorklund (2000) clarified, there are three possible ways to direct the intervention; (1) nurturing, maintaining, enhancing, or modifying inner capacities; (2) mobilizing, improving, or changing environmental conditions; or (3) improving the fit between inner capacities and external circumstances.

What can counselors do to help their clients to deal with their current concerns? Specifically, they can look for particular maladaptive behaviors, help clients to understand them, and then suggest new behaviors that will help them to deal with the difficulty (Tenentes, 1991). Unlike psychotherapy, Adlerian and ego counseling are concerned with relatively normal individuals who function properly in most situations but are troubled by some specific concerns. Its focus is on the reality and the present. Therefore, its goal is oriented toward helping client with today's situation, rather than resolving unconscious conflicts from the client's past experiences. In addition to that, counselors use optimistic and flexible methods to deal with students' environment and personal needs positively rather than being negative and defensive. Ego counselors' methods can be seen favorable and desirable for this integrative practices (Watts \& Pietrzak, 2000; Tenentes, 1991).

\section{Multicultural Domain}

Markstrom and Hunter (1999) highlighted that ideological identity refers to what Erikson called ego identity that includes domains of occupation, religion, politics, and philosophical lifestyle. Ideological concerns are significant to all groups of minority and they dominate ethnic identity. Nevertheless, ideological and ethnic aspects of identity have been assessed separately. Actually ethnic identity might have a stronger weight among minority groups, thus examining ethnic identity among these groups can be considered as beneficial.

With his interest in social inequity, Adlerian theory drove attention to a multicultural perspective. Adler's approach highlights the individual, specifically within a societal and cultural context. Adler defined culture with many dimensions such as age, gender differences, social roles and lifestyle. From this perspective, individual cannot be evaluated independent from their ethnic identity and cultural background. Therefore, individuals discuss and evaluate cultural issues constantly during the counseling process (Corey, 2013). Likewise, Erikson's view includes the aspects of culture and the society that individuals live in, as well. Helping people to increase their awareness about their own culture and help them to define themselves within their culture can be more beneficial to those who need to handle with inferiority feelings.

As it is seen clearly, the aim of the integrative counseling is to make a contribution to ego development as Erikson stated "ego identity" and as Adler stated "creative self". It is inevitable that adjustment and higher self-esteem require ethnic identity; therefore, this important aspect should be considered by counselors. During the counseling process, counselors should help client to describe his or her ethnic identity that include an individual knowledge of membership of a 
social or ethnic group; this way allows the client to better adjust his/her environment or social life.

Besides that, Erikson's psychosocial point of view on personality development refers core elements of multicultural approach. Unlike Freud who viewed human development mostly in an individual context, Erikson stressed the effect of the culture and society on human development. Erikson's referring to the cultural diversity while talking about human instincts points out a multicultural domain. He also stated that youngsters in every culture are directed by older members of the society. Local ceremonies in different cultures (baptism in Christian culture, circumcision in Muslim cultures, transition to manhood ceremonies in African cultures, ect.) helps to build a cultural identity; by alluding this, Erikson drove attention to multicultural sensitiveness. Besides that, experiencing adolescence in an indigenous culture can have important effects on the ego identity of an individual. In the stage of identity conflict (12-18 years) while seeking a society to fix in, the individual may experience severe conflicts especially if the culture $\mathrm{s} / \mathrm{he}$ belongs does not recognized by the majority. S/he may develop radical and intolerant roles as an adult. As a result it can be said that Erikson developed his theory in a multicultural ground.

\section{Limitations of the Integration}

Since the integrated approach focuses on the ethnic identity and addresses contextual and interpersonal processes such as inferiority, it is well suited for multicultural clients. However, it does not provide a process to address discrimination or oppression. Issues of discrimination and oppression can be included this integration with further studies. This integration tries to draw a vague frame about Erikson's and Adler's thoughts about ego psychology and does not provide specific practical methods. Further studies can also discuss and offer more practical methods.

Shaffer (1985) has described two characteristics, which all notable theories share. First, theories must be at the same time concise, as well as applicable to a wide range of phenomena. Second, they must also be precise. That is, they must be capable of making explicit predictions that can be evaluated in later research.

As to the former criterion, integrated approach seems to fall somewhat short of the target. This approach may be very useful for the school counselors. The usefulness of this approach to the practicing school counselors is two-fold. First, the counselor can determine the student's problem by concentrating on the psychosocial conflict or crisis that individual has failed to resolve. Second, once the problem has been determined, the counselor's task is to help the student find better ways of dealing with the reality of the situation -an ego task.

Lastly, the precision of the integrated approach must be improved. Claims have already been stated in this articles are tentative ideas and these should be investigated through qualitative and quantitative methodologies. 


\section{References}

Bjorklund, P. (2000). Assessing ego strength: Spinning straw into gold. Perspectives in Psychiatric Care, 36(1), 14-23.

Corey, G. (2013). Theory and practice of counseling and psychotherapy (9th ed.). California. Brook/Cole Publishing.

Goldstein, E. G. (1995). Ego psychology and social work practice (2nd ed.). New York. The Free Press.

Lee, S. (2002). The effects of peers on the academic and creative talent development of a gifted adolescent male. The journal of Secondary Gifted Education, 14(1), 17-29.

de Man, A. F., \& Efraim, D. P. (1988). Selected personality correlates of social participation in university students. The Journal of social psychology, 128(2), 265-267.

Markstrom, C. A., \& Hunter, C. L. (1999). The roles of ethnic and ideological identity in predicting fidelity in African American and European American adolescents. Child Study Journal, 29(1), 23-39.

Massey, R. F. (1986). Erik Erikson: Neo-Adlerian. Individual Psychology, 42(1), 65.

Prochaska, 0. J. \& Norcross, C. J. (1999). Systems of psychotherapy: A transtheoretical analysis (4th ed.). California. Brooks/Cole Publishing.

Schultz, A., W. \& Liptak, S., G. (1998). Helping adolescents who have disabilities negotiate transitions to adulthood. Comprehensive Pediatric Nursing, 21(4), 187-201

Shaffer, D. R. (1985). Developmental psychology: Theory, research and applications. California: Brooks/Cole Publishing.

Sharf, S., R. (2000). Theories of psychotherapy \& counseling: Concepts and cases (2nd ed.). California. Wadsworth Publishing.

Tenentes, M. (1991). Ego counseling and the behavioral approach: A review of two counseling theories. Guidance \& Counseling, 6(3), 7-22.

Thomas, M., R. (2011). Comparing Theories of Child Development. (6th ed.). California. Wadsworth Publishing.

Watts, R. E. (1996). Social Interest and the Core Conditions: Could It Be That Adler Influenced Rogers?. The Journal of Humanistic Education and Development, 34(4), 165-170.

Watts, R. E., \& Pietrzak, D. (2000). Adlerian "encouragement" and the therapeutic process of solution-focused brief therapy. Journal of Counseling \& Development, 78(4), 442-447.

Weiland, S. (1993). Erik Erikson: Ages, stages, and stories. Generations, 17(2), 17-23. 